\title{
Hotspot of accelerated sea-level rise on the Atlantic coast of North America
}

\author{
Asbury H. Sallenger Jr^, Kara S. Doran and Peter A. Howd
}

\begin{abstract}
Climate warming does not force sea-level rise (SLR) at the same rate everywhere. Rather, there are spatial variations of SLR superimposed on a global average rise. These variations are forced by dynamic processes ${ }^{1-4}$, arising from circulation and variations in temperature and/or salinity, and by static equilibrium processes ${ }^{5}$, arising from mass redistributions changing gravity and the Earth's rotation and shape. These sealevel variations form unique spatial patterns, yet there are very few observations verifying predicted patterns or fingerprints ${ }^{6}$. Here, we present evidence of recently accelerated SLR in a unique 1,000-km-long hotspot on the highly populated North American Atlantic coast north of Cape Hatteras and show that it is consistent with a modelled fingerprint of dynamic SLR. Between 1950-1979 and 1980-2009, SLR rate increases in this northeast hotspot were $\sim 3-4$ times higher than the global average. Modelled dynamic plus steric SLR by 2100 at New York City ranges with Intergovernmental Panel on Climate Change scenario from 36 to $51 \mathrm{~cm}$ (ref. 3); lower emission scenarios project $24-36 \mathrm{~cm}$ (ref. 7). Extrapolations from data herein range from 20 to $29 \mathrm{~cm}$. SLR superimposed on storm surge, wave run-up and set-up will increase the vulnerability of coastal cities to flooding, and beaches and wetlands to deterioration.
\end{abstract}

We test the hypothesis that a statistically significant observed northeast hotspot (NEH) of accelerated SLR exists by determining its position and dimensions and comparing them with model projections ${ }^{1-4}$. We explore correlations between rate changes of observed NEH SLR and of climate indices potentially relevant to NEH formation.

In the late twentieth century, sea levels were relatively low along the North American east coast, particularly north of Cape Hatteras $^{8,9}$. Sea-surface gradients sloped down towards the coast away from the Gulf Stream and its continuation to the northeast, the North Atlantic Current ${ }^{10}$. The sharp pressure gradients balance the Coriolis force to sustain these narrow and strong geostrophic currents, leading to low coastal sea levels.

These low levels could rise with warming and/or freshening of surface water in the subpolar north Atlantic, where less dense water inhibits deep convection associated with the Atlantic Meridional Overturning Current (AMOC). The AMOC weakens and pressure gradients along the North American east coast decrease, raising sea levels. The models considered here simulate this dynamic SLR using Intergovernmental Panel for Climate Change (IPCC) Special Report on Emissions Scenarios warming scenarios ${ }^{2-4}$ and/or assumed freshening scenarios ${ }^{1,4}$. Gyre system weakening by changes in the North Atlantic Oscillation ${ }^{11,12}$ (NAO) could also reduce sea-level gradients and raise sea levels.
To establish the observed NEH, we analyse tide-gauge records along the North American Atlantic coast for increasing rates of SLR (see Methods and Supplementary Information). With leastsquares linear regression, rates of SLR were found for the first and second halves of time-series windows and differenced (for example, Supplementary Fig. S7, equation (2)). We also fitted quadratics to each time-series window, computed accelerations, and showed our results were not sensitive to method. As we are concerned with detecting departures from long-term trends, rate differences, or accelerations, can be compared between gauges without first removing signals that are approximately linear over the time series. Processes contributing solely to the longer-term trend (for example, glacial isostatic adjustment) do not affect our analyses ${ }^{13}$.

Sea-level rate differences (SLRDs) for gauges along the North American east coast show a distinct spatial pattern using time-series windows of 60, 50 and $40 \mathrm{yr}$ (Fig. 1a-c and Supplementary Figs S1 and S2). For $60 \mathrm{yr}$ (1950-2009), the largest SLRDs occur from Cape Hatteras to Boston (mean SLRD $=1.97 \pm 0.64 \mathrm{~mm} \mathrm{yr}^{-1} ; 2 \sigma$; confidence intervals account for serial correlation, equations (3)-(5)). South of Cape Hatteras, SLRDs are not statistically different from zero (mean SLRDs $=0.11 \pm 0.92 \mathrm{~mm} \mathrm{yr}^{-1}$ ), whereas north of Boston, SLRDs are either negative or not different from zero (mean $\left.=-0.94 \pm 0.88 \mathrm{~mm} \mathrm{yr}^{-1}\right)$. The 40-yr window (1970-2009) exhibits the largest mean NEH SLRD $\left(3.80 \pm 1.06 \mathrm{~mm} \mathrm{yr}^{-1}\right)$, and positive differences continue north of Massachusetts and into Canada. For all three durations, SLRDs south of Cape Hatteras are not significantly different from zero. Similar patterns are found for quadratic accelerations (Supplementary Fig. S2).

Mean NEH SLRD is a factor of $\sim 3-4$ larger than global SLRD. For the 60-yr window, the global SLRD during 1950-2009 is 0.59 \pm $0.26 \mathrm{~mm} \mathrm{yr}^{-1}$ (using reconstructed time series ${ }^{14}$ ), compared with NEH SLRD of $1.97 \pm 0.64 \mathrm{~mm} \mathrm{yr}^{-1}$. For the 40 -yr window, global SLRD during 1970-2009 was $0.98 \pm 0.33 \mathrm{~mm} \mathrm{yr}^{-1}$, compared with $\mathrm{NEH}$ SLRD of $3.80 \pm 1.06 \mathrm{~mm} \mathrm{yr}^{-1}$. These strong NEH SLRDs may be associated with AMOC weakening; for observed $\mathrm{NEH}$, model ${ }^{1,3}$ results suggest $\sim 4.4-19 \mathrm{~Sv}$ of weakening by 2100 dependent on scenario and regression window length.

The NEH is unique across coasts of North America between the latitudes of Key West, Florida and St John's, Newfoundland (Fig. 2 and Supplementary Fig. S3). On the Gulf of Mexico and Pacific coasts, most SLRDs using 60-yr windows are not statistically different from zero or are negative (Fig. 2). Results are similar for 50- and 40-yr windows (Supplementary Fig. S3). The lack of positive acceleration through much of North America is consistent with previous results ${ }^{15}$ showing that the recent (about 1990) SLR acceleration occurred mostly in the tropics and the Southern Ocean. 
a

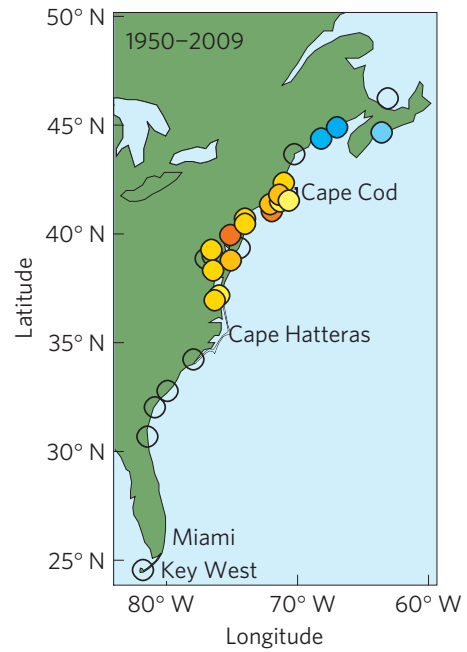

b

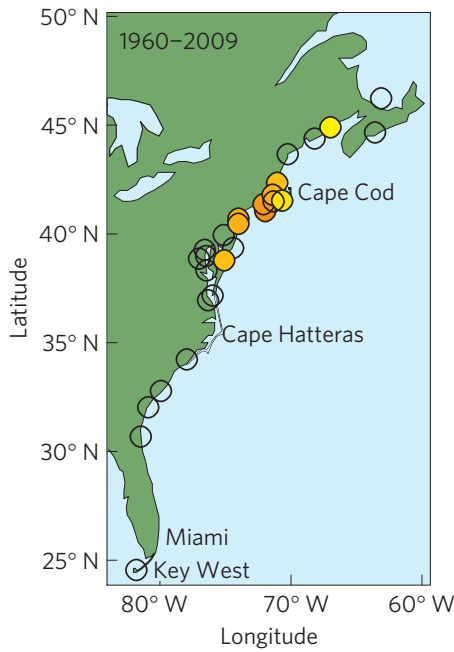

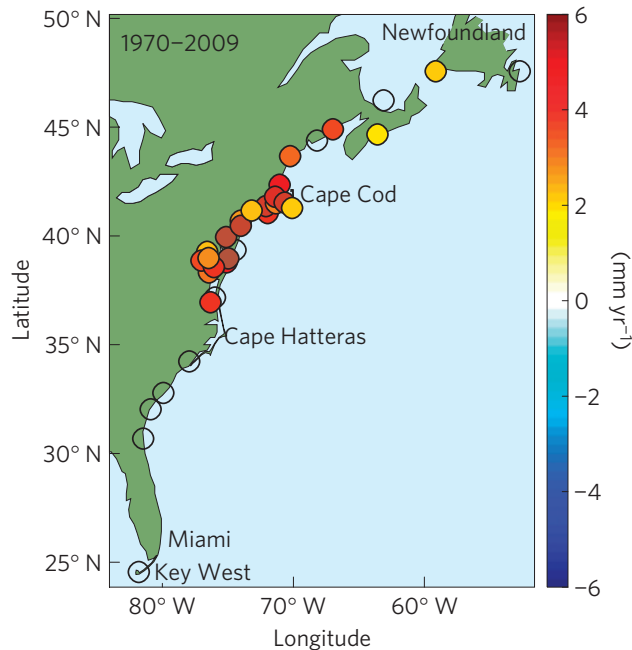

Figure 1 | Spatial variations of SLRD on the North American east coast. Each circle represents a gauge location and is colour-coded to reflect SLRD. Circles with no colour fill are not statistically different from zero. Confidence limits are $\pm 1 \sigma$ and account for serial correlation. More gauges were available for plots that show results from shorter time series. a, 1950-2009. b, 1960-2009. c, 1970-2009.

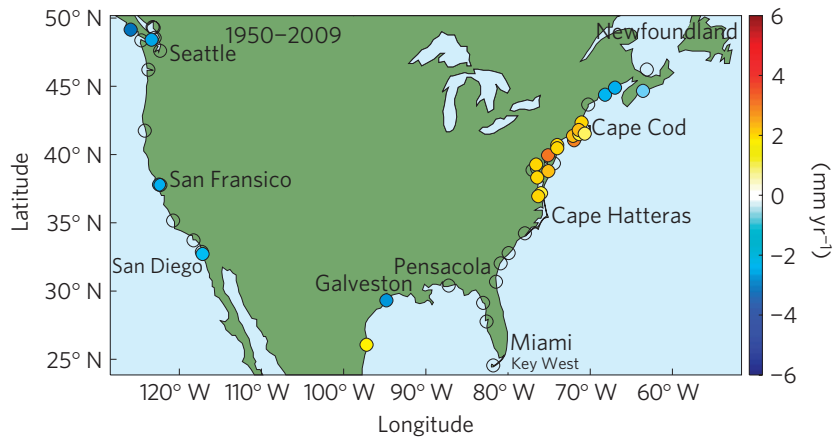

Figure 2 | SLRDs for 60-yr time series at gauge locations across North America. Circles are colour-coded to reflect computed SLRDs; no colour fill indicates SLRDs that are not statistically different from zero. Confidence limits are $\pm 1 \sigma$ and account for serial correlation; 50 - and 40-yr time series results are shown in Supplementary Fig. S3.

The authors of ref. 16 reported 'little regional dependence' of SLR acceleration in the US counter to our detection of a NEH. They found mean negative acceleration for 57 US gauges, including 17 in our observed NEH. Fitting a single quadratic equation for the entire time series available at each station, they calculated average accelerations from gauges having record lengths from 60 to $156 \mathrm{yr}$ and compared them. The spatially averaged SLRDs (and accelerations) in NEH are, however, dependent on time-series length (Fig. 3 and Supplementary Fig. S4). Statistically significant positive SLRDs were detectable in 40-yr (1970-2009) to 72-yr (1938-2009) windows. SLRDs for windows longer than $72 \mathrm{yr}$ were not significantly different from zero. Seventy-six per cent of the NEH data from ref. 16 were longer than $72 \mathrm{yr}$. By using variable record lengths, their results are biased towards SLRDs not statistically different from zero, masking the observed NEH.

The observed NEH is similar to the modelled NEH projected for the end of the twenty-first century ${ }^{2-4}$ and later ${ }^{1}$. A robust prediction across all models is for significantly greater SLR north of Cape Hatteras in agreement with the observed NEH. Using IPCC scenario $\mathrm{A} 1 \mathrm{~B}$, ref. 2 projected $0.1-0.15 \mathrm{~m}$ dynamic SLR (over $\sim 100 \mathrm{yr}$ ) along the coast north of Cape Hatteras and $0.05-0.1 \mathrm{~m}$ south. Using the ensemble mean of ten IPCC Assessment Report 4 models also running scenario A1B, ref. 3 reported $0.15-0.2 \mathrm{~m}$ dynamic SLR (by about 2100) along the coast north of Cape Hatteras and 0.0-0.05 m

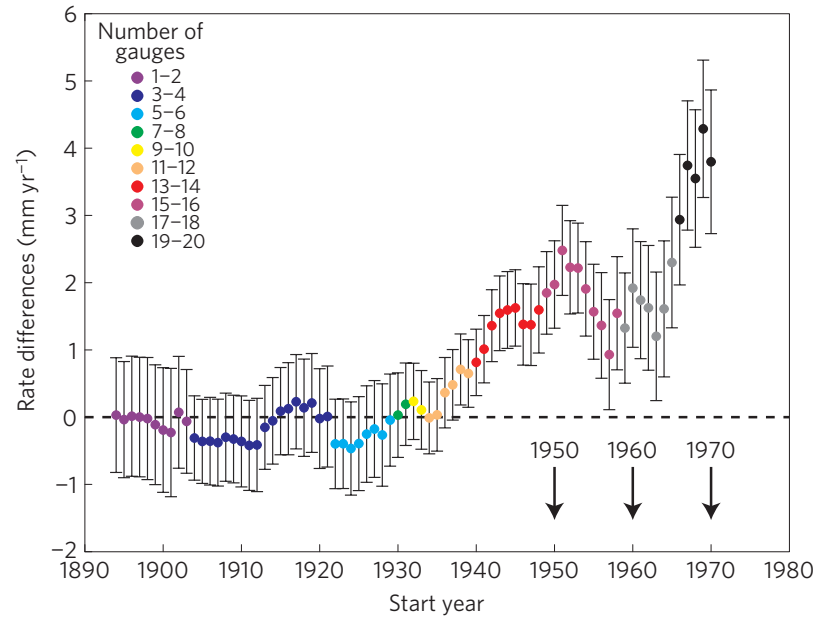

Figure 3 | Dependency of SLRDs on time series lengths for averages of NEH gauges. Confidence limits are $\pm 2 \sigma$ and account for serial correlation. All SLRDs were found for start years (on $x$ axis) to 2009. The most recent start year was 1970, yielding a 40-yr time series; the oldest was 1894, yielding a 115-yr series. The numbers of gauges used in each average are indicated by the colour code. Recent SLRDs are based on averages using up to 21 gauges; the oldest are based on as few as one gauge, NYC.

south. Observed SLRDs were not statistically different from zero south of Cape Hatteras, where the small modelled estimates of SLR were probably undetectable in gauge data. Modelled NEHs generally extended, with variations, north to Newfoundland. Observed NEH varied in northward extent depending on window length; the 40-yr. SLRDs extended the farthest north in closest agreement with models.

The authors of ref. 3 used model results to localize dynamic SLR anomalies for New York City (NYC), projecting 15, 20 and $21 \mathrm{~cm}$ for scenarios B1, A1B and A2 by 2100 (relative to 1981-2000) with ensemble means of multiple models. Using estimates of global steric SLR, they found dynamic plus steric for each scenario, yielding SLRs of 51, 47 and $36 \mathrm{~cm}$. For low-emission scenario model runs (RCP3PD and RCP4.5), ref. 7 found dynamic plus steric SLR for the vicinity of NYC of 24 and $36 \mathrm{~cm}$. These projections are comparable to the twenty-first century extrapolations from our NYC $60-\mathrm{yr}$ SLRD of $\sim 20 \mathrm{~cm}$ and our $40-\mathrm{yr}$ SLRD of $\sim 29 \mathrm{~cm}$ (assuming no 
a

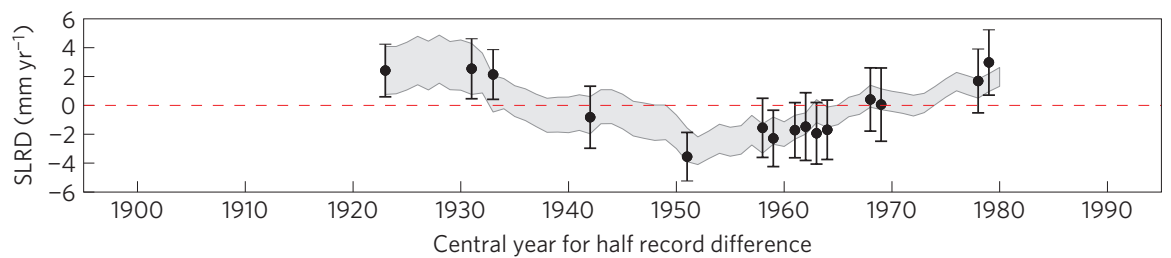

b

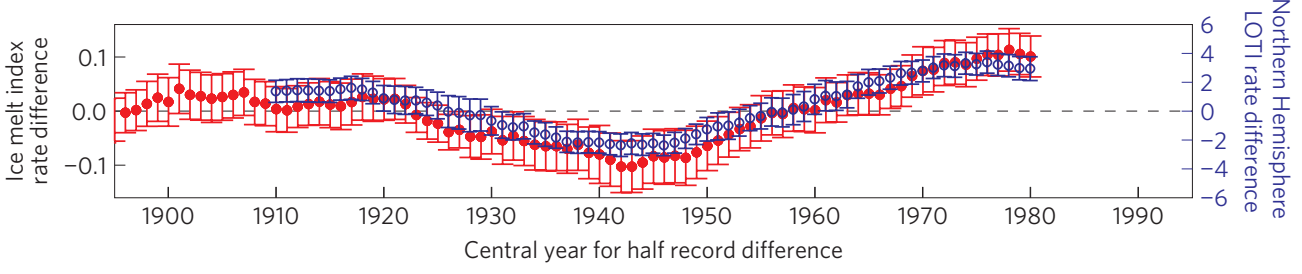

c

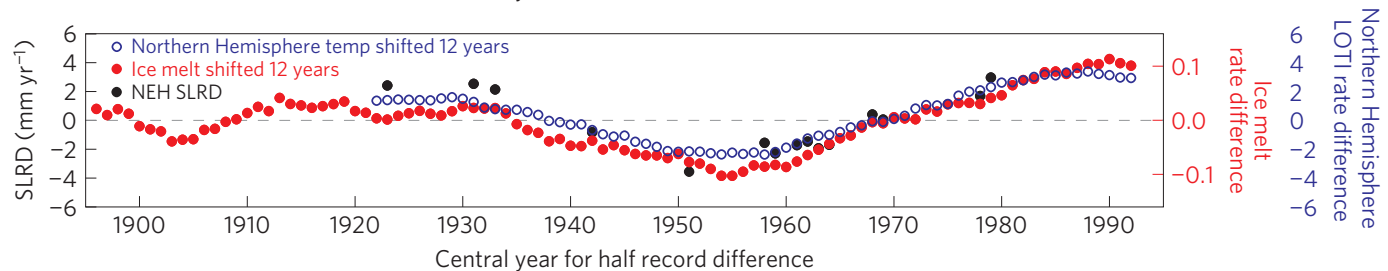

Figure 4 | Comparisons between SLRDs and climate indices. a, A fixed window of $60 \mathrm{yr}$ is shifted $1 \mathrm{yr}$ for each successive calculation. The shaded region is the $2 \sigma$ band surrounding the NEH-averaged SLRDs. Symbols (with $2 \sigma$ error bars) are serially independent SLRDs estimated from individual gauges (see Supplementary Information). b, SLRD time series for the GIS melt index (red) and Northern Hemisphere LOTI (blue) with $2 \sigma$ error bars. c, Independent SLRDs from a (black) with GIS melt index rate differences (red) and Northern Hemisphere LOTI (blue) with both shifted a calculated lag of 12 yr.

future rate changes). The SLRDs include increases from both dynamic and steric SLR (although they probably underestimate steric because of the greater time required for global steric to develop; see Supplementary Information).

We also examine whether subsidence contributed to the observed NEH SLRDs (for example, from increasing groundwater withdrawal increasing subsidence rates over our window lengths yielding nonlinear records). We tested this in two ways. First, we compared SLRDs in areas with relatively high susceptibility to subsidence to SLRDs in areas less susceptible and found them to be statistically the same, suggesting that vertical land motions were approximately linear and did not significantly affect our calculations (see Supplementary Information and Table S2). Second, analyses of global positioning system records measuring land motion near NEH tide gauges have been found to be approximately linear, although records were relatively few and short $^{17}, \sim 10 \mathrm{yr}$.

The timing of NEH formation can be inferred from Fig. 3, where the general increase in SLRDs from start dates in the 1930s-1970 (with uniform end dates of 2009) could reflect a recent increase in the rate of SLR. The magnitude of the SLRD would increase as the regression window narrows and the centre point of the window approaches the date of the rate increase (Fig. 3 and Supplementary Fig. S5). This suggests that the increase occurred about or after 1990 (that is, with an inflection point about or after midway of a window with start year 1970 and end year 2009). Hence, the rate increase is coincident with the onset of accelerating global SLR in the early 1990s (refs 14,15).

Whereas the NEH was unique spatially for much of North America, it was not unique temporally. The evolution of SLRDs in the NEH through much of the twentieth century is shown in Fig. 4a using a constant 60-yr window. (A method was employed to maximize the number of independent estimates; see Supplementary Information.) We explore lagged cross-correlations from the 1920s to near present with temperature-based parameters that may indicate high-latitude North Atlantic warming, and rising surface water buoyancy, that could slow AMOC. We find rate differences of Northern Hemisphere temperature (Land and Ocean Temperature
Anomaly Index, or Northern Hemisphere LOTI: Fig. 4b,c and Supplementary Fig. S9B) explain 91\% of the variance of $\mathrm{NEH}$ SLRDs $\left(r^{2}=0.91 ; 12\right.$ yr lag; positive indicates Northern Hemisphere LOTI rate difference leads SLRD). We find similar results with rate differences of global temperature (that is, global LOTI: $r^{2}=0.92 ; 12$ yr lag). Good correlations were also found with rate differences of other temperature-based parameters such as Atlantic Multidecadal Oscillation (AMO) and Greenland summer coastal temperatures (AMO: $r^{2}=0.92 ; 8$ yr lag; Supplementary Fig. S9C; Greenland coastal temperatures: see Supplementary Information; $r^{2}=0.88 ; 12$ yr lag).

In addition to the warming effects of temperature, ice melt could freshen surface water, further reducing its buoyancy, for example, in the deepwater formation area south of Greenland. The authors of ref. 18 detected acceleration of Greenland ice sheet (GIS) melt of $21.9 \pm 1 \mathrm{Gt} \mathrm{yr}^{-2}$ that began in the early 1990s, roughly coincident with $\mathrm{NEH}$ initiation. Investigators have developed indexes for GIS melt through multiple regression of forcing parameters with dependent estimates of melt from satellite measurements over the past few decades ${ }^{19-21}$. We use the recent index of ref. 19 (see equation (1) and Supplementary Information) based on Greenland coastal summer temperatures and winter NAO. (Seawater temperature is not included and may be important to GIS melt from below $^{22,23}$.) With a 12-yr lag, ice melt rate differences explained $84 \%$ of the variance of SLRDs (Fig. 4b,c and Supplementary Fig. S9A; $r^{2}=0.84$; lag $=12 \mathrm{yr}$ ). The relatively short lag is consistent with model projections ${ }^{24}$. The good agreement results mostly from the Greenland temperature term (compare correlation for ice melt to correlation for Greenland temperatures alone).

The atmospheric NAO rate differences may indicate changes in strength of the gyre system. However, NAO rate differences explain only $30 \%$ of the NEH SLRDs (Supplementary Fig. S9D), and hence NAO may not contribute to forcing the NEH. The authors of ref. 2 found that $\mathrm{NAO}$ variations were consistent with variations in gyre transport before about 1940, but not after that time and through their simulations to 2100 .

Aerosols may also play a role in explaining variations in NEH SLRDs. The mid-century low (Fig. 4) may have been 
forced by volcanic aerosols reflecting radiation and lowering air temperatures ${ }^{25}$ and slowing ${ }^{14}$ SLR. The authors of ref. 26 found $76 \%$ of the variance of detrended North Atlantic sea surface temperatures from 1860-2005 could be explained by aerosol emissions and volcanic eruptions. In regard to the role of cycles, the single $\sim 60$-yr pattern in Fig. 4a does not seem associated with 10-30 yr sea-level variations discussed in ref. 27. With our limited series length, the presence of cycles, for example associated with natural ocean variability and/or AMO, is indeterminate. In the Holocene geologic record of an NEH marsh, the authors of ref. 28 found evidence of several rapid SLR increases separated by $900 \mathrm{yr}$ or more that they associated with gyre changes. Regardless, our correlations suggest that should temperatures rise in the twenty-first century as projected, the NEH SLRD will continue to increase. If future sea-level variability is forced by aerosols and/or is part of a cycle, SLR in the NEH may also alternately fall below and rise above projections of IPCC scenarios alone.

Our analyses support a recent acceleration of SLR on $\sim 1,000 \mathrm{~km}$ of the east coast of North America north of Cape Hatteras. This hotspot is consistent with SLR associated with a slowdown of AMOC.

\section{Methods}

The tide-gauge data used in this study were annual mean sea-level time series downloaded from the Permanent Service for Mean Sea Level web site (www.psmsl. org) in March 2011. By December 2011, some of the Permanent Service for Mean Sea Level tide stations used here had not been updated with data through 2010. Hence, for internal consistency, we use data for all gauges only up to, but not including, 2010; the last annual mean value corresponds to calendar year 2009. Further details can be found in the Supplementary Information.

The global sea-level reconstruction ${ }^{14}$ for $1880-2009$ was downloaded from www.cmar.csiro.au/sealevel/sl_data_cmar.htmlin August 2011.

GIS index was calculated using the model described in ref. 19

$$
\operatorname{GIM}(t)=-5.84+0.09 *(4 \operatorname{Temp}(t))+0.21 *(\mathrm{NAO}(t))
$$

where 4Temp is comprised of the June-August average temperatures from Ilullisat, Nuuk and Qaqortoq for 1784-1895 and Ilullisat, Nuuk, Qaqortoq and Tasilaq for 1895-2010. NAO is the December, January and February averaged NAO index.

The merged Greenland averaged monthly (June-August) temperatures from Ilulissat, Nuuk and Qaqortoq used for 1784-1895 were downloaded from www. cru.uea.ac.uk/cru/data/greenland/swgreenlandave.dat. The merged Greenland averaged monthly (June-August) temperatures from Ilulissat, Nuuk and Tasiilaq for 1895-2010 were downloaded from the Danish Meteorological Institute (www. dmi.dk/dmi/tr11-05.pdf). Qaqortoq data were obtained from http://cdo.ncdc. noaa.gov/pls/plclimprod/poemain.accessrouterand the NAO time series from www.cru.uea.ac.uk/cru/data/nao/.

We use a rate-based method to calculate a time series of SLRD between the two adjacent intervals of the record given by

$$
\operatorname{SLRD}\left(t_{\mathrm{c}}, \tau\right)=\beta_{2}\left(t_{2}, \tau\right)-\beta_{1}\left(t_{1}, \tau\right)
$$

where $\beta_{1}$ and $\beta_{2}$ are the linear regression slopes and $t_{1}$ and $t_{2}$ are the start times of the first and second halves of a total regression window with duration $\tau$. $t_{\mathrm{c}}$, the central time associated with the estimate, is taken as the first date of the second half, that is, the first date in $t_{2}$. If $\tau$ is chosen to be less than the total record length, the analysis may be repeated after shifting $t_{1}$ and $t_{2}$ by an interval of $\Delta \tau$. The SLRD calculation may be repeated until $t_{\mathrm{c}}+\tau / 2$ reaches the last measurement date, giving the time series of equation (2). If $\Delta \tau<t$, the time-stepped regression windows overlap and it is necessary to remember that some of the resulting points in $\operatorname{SLRD}\left(t_{\mathrm{c}}, \tau\right)$ will not be independent as they have underlying sea-level data points in common.

Standard errors on the regression coefficients are given by:

$$
\sigma\left(\beta_{i}\right)=\sqrt{\frac{\mathrm{RSS}}{N_{\mathrm{r}}}\left(\left[\mathbf{X}^{\mathrm{T}} \mathbf{X}\right]^{-1}\right)_{j j}}
$$

where $\sigma\left(\beta_{i}\right)$ is the standard error of the $i$ th parameter estimate $(i=j-1)$, RSS is the sum of squares of the residuals, $N_{r}$ is the number of degrees of freedom appropriate for the regression model and $\mathbf{X}$ is the matrix of basis functions used in the regression model. $\sigma\left(\beta_{i}\right)$ is multiplied by 2.0 to obtain the $95 \%$ confidence interval about the regression coefficient.
Time series were tested for serial correlation using the Durbin-Watson statistic $^{29}$ and the results indicate significant autocorrelation for the data used here. We are interested in the low-frequency components and, unlike ref. 29, we choose to correct our error estimates for the influence of serial correlation rather than use a filtering methodology. We estimate an effective number of data points $\left(N_{\text {eff }}\right)$ to replace $N$ in the typical representation of $N_{r}=N-j$ ( $N$ is the number of data points used in the regression model and $j$ is the number of estimated coefficients). The authors of ref. 30 suggest a method of calculating $N_{\text {eff }}$ for annual mean sea-level measurements using the lag-1 autocorrelation $\left(r_{1}\right)$ :

$$
N_{\text {eff }}=N \frac{1-r_{1}}{1+r_{1}}
$$

We can calculate the lag- 1 autocorrelation directly, but it is not a stable estimate for noisy time series. Instead, we fit an $\operatorname{AR}(1)$ model to the residuals and use the $\operatorname{AR}(1)$ coefficient for $r_{1}$. A typical value for the AR(1) coefficient is $\sim 0.40$ and the effect of serial correlation is to amplify the standard error of the parameter by a factor of $\sim 1.5$. Of course, this amplification varies on a model-to-model basis and this value is meant only as general guidance.

The standard error of SLRD is calculated as:

$$
\sigma_{\mathrm{SLRD}}\left(t_{\mathrm{c}}, \tau\right)=\sqrt{\sigma_{\mathrm{HR} 1}^{2}\left(t_{\mathrm{c} 1}, \frac{\tau}{2}\right)+\sigma_{\mathrm{HR} 2}^{2}\left(t_{\mathrm{c} 2}, \frac{\tau}{2}\right)}
$$

where the standard errors of the half-records (HR1 and HR2) are calculated as given above. $\sigma_{\text {SLRD }}$ is multiplied by a factor of 2.0 to obtain $95 \%$ confidence intervals. Further details are provided in the Supplementary Information.

\section{Received 23 January 2012; accepted 22 May 2012; published online 24 June 2012}

\section{References}

1. Levermann, A., Griesel, A., Hofmann, M., Montoya, M. \& Rahmstorf, S. Dynamic sea level changes following changes in the thermohaline circulation. Clim. Dynam. 24, 347-354 (2005).

2. Landerer, F. W., Jungclaus, J. \& Marotzke, J. Regional dynamic and steric sea level change in response to the IPCC-A1B scenario. J. Phys. Oceanogr. 37, 296-312 (2007).

3. Yin, J., Schlesinger, M. E. \& Stouffer, R. J. Model projections of rapid sea-level rise on the northeast coast of the United States. Nature Geosci. 2, 262-266 (2009).

4. Hu, A., Meehl, G., Han, W. \& Yin, J. Effect of the potential melting of the Greenland Ice Sheet on the meridional overturning circulation and global climate in the future. Deep-Sea Res. II 58, 1914-1926 (2011).

5. Mitrovica, J. X., Tamisiea, M. E., Davis, J. L. \& Milne, G. A. Recent mass balance of polar ice sheets inferred from patterns of global sea-level change. Nature 409, 1026-1029 (2001)

6. Douglas, B. C. Concerning evidence for fingerprints of glacial melting. J. Coast. Res. 24, 218-227 (2008).

7. Schleussner, C. F., Frieler, K., Meinshausen, M., Yin, J. \& Levermann, A. Emulating Atlantic overturning strength for low emission scenarios: Consequences for sea-level rise along the North American east coast. Earth Syst. Dynam. 2, 1-10 (2011).

8. Maximenko, N. et al. Mean dynamic topography of the ocean derived from satellite and drifting buoy data using three different techniques. J. Atmos. Ocean. Tech. 26, 1910-1919 (2009).

9. Rio, M-H. \& Hernandez, F. A mean dynamic topography computed over the world ocean from altimetry, in situ measurements, and a geoid model. J. Geophys. Res. 109, C12032 (2004).

10. Krauss, W. The North Atlantic current. J. Geophys. Res. 91, 5061-5074 (1986).

11. Curry, R. G. \& McCartney, M. S. Ocean gyre circulation changes associated with the North Atlantic Oscillation. J. Phys. Oceanogr. 31, 3374-3400.

12. Hakkinen, S. \& Rhines, P. B. Decline of subpolar North Atlantic circulation during the 1990s. Science 304, 555-559 (2004).

13. Douglas, B. C. in Sea Level Rise: History and Consequences (eds Douglas, B. C., Kearney, M. S. \& Leatherman, S.P.) 37-64 (Inter. Geophys. Ser., Vol. 75, Academic, 2001).

14. Church, J. A. \& White, N. J. Sea-level rise from the late 19th to the early 21st Century. Surv. Geophys. 32, 585-602 (2011).

15. Merrifield, M. A., Merrifield, S. T. \& Mitchum, G. T. An anomalous recent acceleration of global sea level rise. J. Clim. 22, 5772-5781 (2009).

16. Houston, J. R. \& Dean, R. G. Sea-level acceleration based on US tide gauges and extensions of previous global-gauge analyses. J. Coastal Res. 27, 409-417 (2011).

17. Doran, K. J. Addressing the Problem of Land Motion at Tide Gauges, M. S. thesis 1616, College of Marine Science, Univ. South Florida (2010).

18. Rignot, E., Velicogna, I., van den Broeke, M. R., Monaghan, A. \& Lenaerts, J. Acceleration of the contribution of the Greenland and Antarctic ice sheets to sea level rise. Geophys. Res. Lett. 38, L05503 (2011). 
19. Frauenfeld, O. W., Knappenberger, P. C. \& Michaels, P. J. A reconstruction of annual Greenland ice melt extent, 1784-2009. J. Geophys. Res. 116, D08104 (2011).

20. Abdalati, W. \& Steffen, K. Greenland ice sheet melt extent: 1979-1999. J. Geophys. Res. 106, 33983-33989 (2001).

21. Mote, T. L. Greenland surface melt trends 1973-2007: Evidence of a large increase in 2007. Geophys. Res. Lett. 34, L22507 (2007).

22. Rignot, E., Koppes, M. \& Velicogna, I. Rapid submarine melting of the calving faces of West Greenland glaciers. Nature Geosci. 3, 187-191 (2010).

23. Yin, J. et al. Different magnitudes of projected subsurface ocean warming around Greenland and Antarctica. Nature Geosci. 4, 524-528 (2011).

24. Yin, J., Griffies, S. \& Stouffer, R. Spatial variability of sea level rise in twenty-first century projections. J. Clim. 23, 4585-4607 (2010).

25. Box, J. E., Yang, L., Bromwich, D. H. \& Bai, L-S. Greenland ice sheet surface air temperature variability: 1840-2007. J. Clim. 22, 4029-4049 (2009).

26. Booth, B. B. B. et al. Aerosols implicated as a prime driver of twentieth-century North Atlantic climate variability. Nature 484, 288-232 (2012).

27. Frankcombe, L. \& Dijkstra, H. Geophys. Res. Lett. 36, L15604 (2009).

28. Fletcher II, C. H., Van Pelt, J. E., Brush, G. S. \& Sherman, J. Tidal wetland record of Holocene sea-level movements and climate history. Palaeogeogr. Palaeoclimatol. Palaeoecol. 102, 177-213 (1993).

29. Boon, J. D., Brubaker, J. M. \& Forrest, D. R. Chesapeake Bay Land Subsidence and Sea Level Change: An Evaluation of Past and Present Trends andFuture
Outlook Special Report No. 425 in Applied Marine Science and Ocean Engineering (Virginia Institute of Marine Science, 2010).

30. Maul, G. A. \& Martin, D. M. Sea level rise at Key West, Florida, 1846-1992: America's longest instrument record? Geophys. Res. Lett. 20, 1955-1958 (1993).

\section{Acknowledgements}

The USGS Coastal and Marine Geology Program provided the financial support for this work. We thank the following for providing comments on our manuscript before submission: R. A. Holman, J. Boon, C. Fletcher, N. Plant, E. R. Thieler, L. Robbins and J. List. We also thank G. Mitchum, P. Thompson and J. Haines for useful discussions about dynamic SLR and results presented in this paper. K. Morgan assisted with preparation of the final figures.

\section{Author contributions}

A.H.S. conceived the study, developed hypotheses and tests, supervised the work and wrote the main text. K.S.D. conducted the calculations, and posed and carried out sensitivity and statistical tests. P.A.H. designed statistical tests, developed/tested methods and wrote the Methods and Supplementary Information.

\section{Additional information}

The authors declare no competing financial interests. Supplementary information accompanies this paper on www.nature.com/natureclimatechange. Reprints and permissions information is available online at www.nature.com/reprints. Correspondence and requests for materials should be addressed to A.H.S. 